\title{
Atypical sites of lymphoma in the central nervous system
}

\author{
Ricardo Schwingel' , Fabiano Reis², Veronica Zanardi², \\ Luciano Queiroz ${ }^{3}$, Marcondes França Jr ${ }^{4}$
}

\section{CASE}

A 51-year-old immunocompetent man presented left-side third nerve palsy. He had previously been diagnosed eight years earlier with an axillary large-cell nonHodgkin lymphoma (NHL), which had been treated with chemotherapy and radiotherapy. MRI showed pineal and hypothalamic lesions (Fig A and B) and computed tomography of the abdomen showed a spleen lesion. After splenectomy, the diagnosis of NHL was made. Labora- tory findings showed enhanced serum lactate dehydrogenase (LDH) levels (594 U/l; reference value: $479 \mathrm{U} / \mathrm{l}$ ) and enhanced IgG levels in the cerebrospinal fluid (15.4 mg/ $\mathrm{dl}$; reference value: $3.4 \mathrm{mg} / \mathrm{dl}$ ). Increased protein content and cell counts in the cerebrospinal fluid were also observed. The patient was treated with chemotherapy. Eleven months later, the pineal and hypothalamic lesions had disappeared, but a lesion had appeared in the right inferior horn of the right lateral ventricle (Fig C and D). 


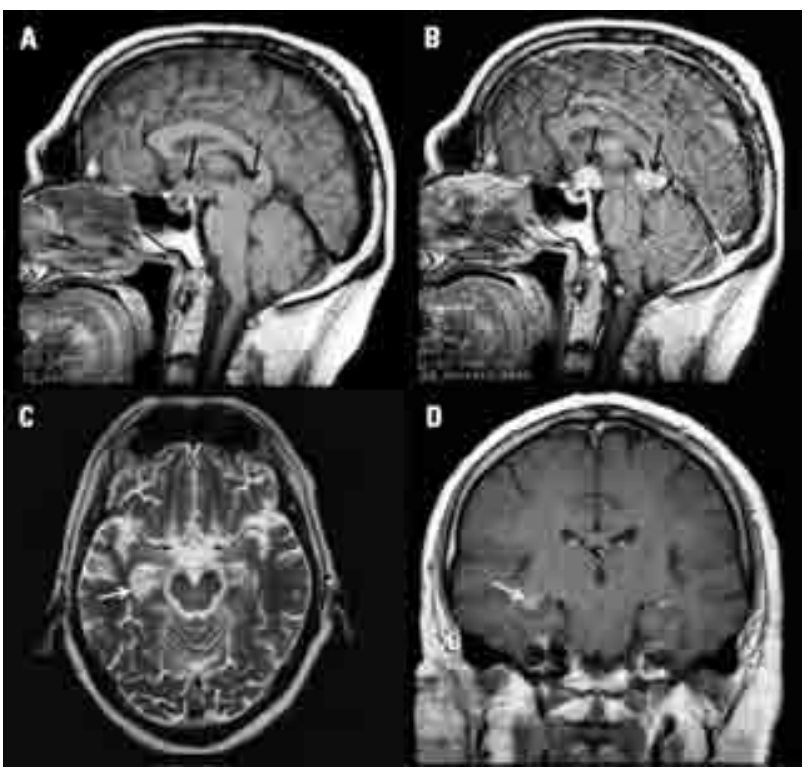

Figure. Sagittal T1-weighted images before [A] and after contrast $[B]$, showing isointense lesions in the pineal and hypothalamic regions, with intense enhancement (arrows); axial T2-weighted image $[\mathrm{C}]$ showing hyperintense lesion in the right temporal horn (arrow); coronal T1-weighted image after contrast [D], showing homogeneous enhancement (arrow).

Shortly afterwards, the patient's clinical condition deteriorated and he died.

\section{DISCUSSION}

In a case of pineal gland lymphoma reported in the literature, the lesion appeared to be similar to primary tumors of pineal origin (pineocytoma and pineoblastoma), or even to germinoma (which may also show an intermediate signal on $\mathrm{T} 1$ and hypointense signal on T2, due to a high nucleus/cytoplasm ratio) ${ }^{1}$. However, germinoma is a tumor of adolescence and young adulthood. A second case showed a lesion with cystic and nodular components simultaneously ${ }^{2}$. Imaging examinations may also show heterogeneous enhancement with thick nodular enhancement of the leptomeninges ${ }^{3}$.

In a case of lymphoma in the hypothalamic region, the lesion appeared to be hypointense on T1-weighted images and showed intense and homogeneous enhancement after contrast injection ${ }^{4}$. Two other cases reported isointense masses on T1-weighted images, with heterogeneous contrast enhancements and erosion of surrounding bone structures ${ }^{5}$. Infundibulum metastases are usually isointense on T1-weighted images and are enhanced by contrast. On T2, lymphoma in the hypothalamic and pineal region may show hypointensity due to a high nucleus/cytoplasm ratio, as we observed in our patient.
Although the histological diagnosis can often be suspected from the radiological characteristics of the lesion, few pineal and hypothalamic tumors have pathognomonic imaging patterns. Histological diagnosis is necessary for primary tumors, because both regions can be affected independently by a variety of benign and malignant tumors. Our patient was not subjected to biopsy of the intracranial tumor, but the diagnosis of lymphoma was plausible, because of his clinical history and high LDH level, and because of the disappearance of the lesion after chemotherapy for the concurrent lymphoma, as confirmed by the spleen biopsy. However, after 11 months, a lesion was detected in the choroid plexus, another rare site for occurrences of lymphoma.

In conclusion, we have presented a case with atypical sites for CNS lymphoma occurrence. This diagnosis should be considered if the patient has previously had systemic lymphoma, with involvement of more than one extranodal site and a high LDH level (which are the main independent risk factors for recurrence of lymphoma in the CNS), and later develops important symptoms for a diagnosis of tumor recurrence in the CNS. Although such radiological findings are unusual, they may aid the diagnostic differentiation, particularly if the lesion shows a hypointense signal on $\mathrm{T} 2$.

\section{REFERENCES}

1. Erdag N, Bhorade RM, Alberico RA, Yousuf N, Patel MR. Primary lymphoma of the central nervous system: typical and atypical CT and MR imaging appearances. AJR 2001;1176:1319-1326.

2. Endo H, Fujimura M, Kumabe T, Kanamori M, Watanabe M, Tominaga T. Application of high-definition flexible neuroendoscopic system to the treatment of primary malignant B-cell lymphoma. Surg Neurol 2009;71: 344-348.

3. Karikari IO, Thomas KK, Lagoo A, Cummings TJ, George TM. Primary cerebral ALK-1-positive anaplastic large cell lymphoma in a child: case report and literature review. Pediatr Neurosurg 2007;43:516-521.

4. Chourmouzi D, Boulogianni G, Delaroudis S, Drevelegas A. Hypopituitarism due to hypothalamic B-cell lymphoma. JBR-BTR 2005;88:116-117.

5. Kaufmann TJ, Lopes MB, Laws ER Jr, et al. Primary sellar lymphoma: radiologic and pathologic findings in two patients. AJNR Am J Neuroradiol 2002;23:364-367.

\section{LOCAIS ATÍPICOS DE LINFOMA NO SISTEMA NERVOSO CENTRAL}

Departments of Radiology (RS, FR, VZ), Pathology (LQ) and Neurology (MFJr), School of Medical Sciences, State University of Campinas (UNICAMP), Campinas SP, Brazil: 'Medical Student, UNICAMP; ${ }^{2}$ MD, PhD, Professor, Department of Radiology; ${ }^{3} \mathrm{MD}$, PhD, Professor, Department of Pathology; ${ }^{4} \mathrm{MD}, \mathrm{PhD}$, Professor, Department of Neurology.

Correspondence: Fabiano Reis - Faculdade de Ciências Médicas, Universidade Estadual de Campinas, Departamento de Radiologia - Rua Tessália Vieira de Camargo 126 - 13083-887 Caixa Postal 6111 - Cidade Universitária Zeferino Vaz Campinas SP - Brazil. E-mail: fabianoreis2@gmail.com

Support: FAPESP process no. 2010/01939-0.

Received 6 January 2011. Received in final form 10 March 2011. Accepted 18 March 2011. 